\title{
Pelayanan Makanan dan Minuman Pada Pesta Pernikahan Masyarakat Adat Sebagai Daya Tarik Pariwisata Berbasis Masyarakat
}

\author{
Ramdah Radjab ${ }^{1}$, Dewa Made Dirga ${ }^{2}$, I Nyoman Arcana ${ }^{3}$, Mandra $^{4}$, \\ Herlina $^{5}$, Rizda Endean N. Batubara ${ }^{6}$ \\ 1,2,4,5,6 Program Studi Tata Hidang, Politeknik Pariwisata Lombok \\ Jalan Raden Puguh No 1, Puyung, Lombok Tengah, Nusa Tenggara Barat, Indonesia \\ ${ }^{3}$ Program Studi Manajemen Tata Hidangan, Politeknik Pariwisata Bali \\ Jl. Darmawangsa, Kampial, Kuta Selatan, Bali \\ ${ }^{1}$ ramdah@ppl.ac.id, ${ }^{2}$ dewadirga85@yahoo.com, ${ }^{3}$ arcananyoman@gmail.com \\ ${ }^{4}$ mandra.kawo@gmail.com, ${ }^{5}$ herlina.juli86.@gmail.com, 6batubararizda@gmail.com
}

Received: November, 2020 $\quad$ Accepted: November, 2020 $\quad$ Published: December, 2020

\begin{abstract}
The diversity of ethnic groups in Indonesia creates a diversity of cultural expressions. Among them are the Baduy Luar Tribe in Kanekes Village, Banten Province, Toba Batak Tribe which occupying Samosir Island, North Sumatra, and Sasak Tribe on Lombok Island. This study aims to examine the tradition of food and beverage service at traditional weddings of indigenous peoples as a communitybased tourism attraction, which includes the procession of food and beverage service preparation This study resulted in the following findings, namely: 1 . The philosophy implied in the stages of the third wedding party shows that the culture of the Toba Batak people is influenced by Dutch (European) culture, while the culture of the Baduy Luar community is influenced by the natural environment where they live from generation to generation., and the culture of the Sasak people combines well with the relationship between customs and Islamic culture, and; 2.Indicators of food and beverage service at the wedding of the Toba Batak, Baduy Luar, and Sasak people that have the potential to become community-based tourism. This study recommends that the preparation of wedding party food and beverage services in traditional communities apply the CHSE standard for the health of the guests and families of the bride and groom, as well as to fulfill the requirements to become a community-based tourism attraction.
\end{abstract}

Keywords: cultural diversity, food and beverage service, traditional wedding party, community-based tourism attraction.

\footnotetext{
Abstrak

Keberagaman suku bangsa di Indonesia menciptakan keragaman ekspresi budaya. Diantaranya adalah Suku Baduy Luar di Desa Kanekes, Provinsi Banten, Suku Batak Toba yang mendiami Pulau Samosir, Sumatera Utara, dan Suku Sasak di
} 
Pulau Lombok. Penelitian ini bertujuan untuk mengkaji tradisi pelayanan makanan dan minuman pada pernikahan adat masyarakat adat sebagai daya tarik wisata berbasis masyarakat, yang meliputi prosesi persiapan pelayanan makanan dan minuman Penelitian ini menghasilkan temuan sebagai berikut: 1. Filosofi tersirat dalam tahapan pesta pernikahan ketiga menunjukkan bahwa budaya masyarakat Batak Toba dipengaruhi oleh budaya Belanda (Eropa), sedangkan budaya masyarakat Baduy Luar dipengaruhi oleh lingkungan alam tempat mereka tinggal secara turun temurun., dan budaya orang Sasak berpadu baik dengan hubungan adat dan budaya Islam, dan; 2.Indikator pelayanan makanan dan minuman pada acara pernikahan masyarakat Batak Toba, Baduy Luar, dan Sasak yang berpotensi menjadi wisata berbasis masyarakat. Penelitian ini merekomendasikan agar penyusunan layanan makanan dan minuman pesta pernikahan di masyarakat adat menerapkan standar CHSE untuk kesehatan para tamu dan keluarga calon pengantin, serta memenuhi syarat untuk menjadi daya tarik wisata berbasis masyarakat.

Kata kunci: keragaman budaya, pelayanan makanan dan minuman, pesta pernikahan tradisional, daya tarik wisata berbasis masyarakat.

\section{PENDAHULUAN}

Indonesia adalah negara kepulauan (archipelago) yang memiliki jumlah pulau terbanyak ke 5 di dunia dengan jumlah 17.508 buah pulau. Dikutip dari sumber www.worldatlas.com, Swedia adalah negara yang memiliki pulau terbanyak, yaitu 257.570 buah pulau, kemudian Norwegia dengan 239.057 buah pulau, ditempat ketiga adalah Finlandia dengan 178.947 buah pulua, dan peringkat ke empat adalah Kanada dengan 52.455 buah pulau. Menurut data dari Direktorat Jenderal Pemerintahan Umum, Indonesia tercatat memiliki 17.500 pulau dan 16.056 diantaranya telah memiliki nama baku di PBB (United Nations). Banyaknya pulau yang dimiliki oleh Indonesia, menjadikan Indonesia juga memilki banyak suku, bahasa, dan budaya.

Menurut Data BPS tahun 2010, Indonesia memiliki 1.340 suku bangsa atau kelompok etnik. Baduy Luar hidup dengan budaya dan adat yang masih asli dari jaman leluhurnya sejak ribuan tahun lampau hingga hari ini. Batak Toba, khususnya desa Tomok, bertempat tinggal di Kabupaten Samosir. Suku Batak di Samosir adalah sub atau bagian dari suku bangsa Batak Toba dan memiliki wilayah sekitar pulau Samosir. Selanjutnya di Pulau Lombok terdapat wisata budaya masih tetap alami, dengan tradisi dari suku Sasak yang memilki tradisi budaya yang kuat dengan desa adat yang masih setia dengan budaya asli Sasak, seperti Desa Rembitan di Kecamatan Pujut, Kabupaten Lombok Tengah.

Keberagaman budaya daerah merupakan salah satu daya tarik utama pariwisata Indonesia disamping keindahan alam. Selain kaya dengan berbagai khazanah budaya daerah, Kepulauan Nusantara juga dikenal sebagai asal muasal dari salah satu model peyalanan perjamuan makanan dan minuman.

Salah satu contoh budaya pelayanan makanan dan minuman asli Nusantara yang sekarang telah popular sebagai model pelayanan mewah di restoran bagi wisatawan adalah pelayanan "Rijsttafel. Rijsttafel (dibaca "rèisttafel" secara harfiah dalam Bahasa Belanda berarti "meja nasi") merupakan cara penyajian makanan berurutan dengan pilihan hidangan dari berbagai daerah di Nusantara. Cara 
penyajian seperti ini berkembang pada masa kolonial Hindia Belanda yang memadukan etiket dan tata cara perjamuan resmi Eropa dengan kebiasaan makan penduduk setempat yang mengkonsumsi nasi sebagai makanan pokok dengan berbagai lauk-pauknya. Cara penyajian ini populer di kalangan masyarakat EropaIndonesia, namun tetap digemari di Belanda dan dihidupkan lagi di Indonesia pada masa kini.

Meskipun masakan yang disajikan adalah masakan Indonesia, asal-mula rijsttafel adalah sejarah kolonial. Pada masa kolonial Hindia Belanda, para penguasa dan orang kaya Belanda menciptakan perjamuan ini sebagai sarana untuk menikmati beraneka ragam makanan Nusantara dalam satu kesempatan, sekaligus untuk membuat para tamu terkesan dengan memamerkan kekayaan dan kemakmuran koloninya (Wikipedia, 2020). Lebih bersifat sebagai jamuan pesta pada era Kolonial Belanda, rijsttafel diciptakan sebagai bentuk perjamuan resmi (makan siang atau makan malam) yang meriah yang dapat mewakili keanekaragaman suku-bangsa di Nusantara. Aneka macam hidangan dihimpun dari penjuru negeri; khazanah kuliner khas dari berbagai pulau di Indonesia

Dari sekian banyaknya tehnik pelayanan makanan dan minuman otentik Indonesia, belum didata adanya standar pelayanan yang dapat digunakan sebagai standar pelayanan dalam bisnis hospitaliti di Indonesia, yang dapat menjadi acuan pendidikan atau penyususnan Sequence of Services (SoS). Oleh karena itu, penelitian ini mencoba memetakan berbagai indikator pada pesta penyajian makanan dan minuman pada ke tiga komunitas suku tersebut yang berpotensi untuk dijadikan model pelayanan makanan dan minuman otentik Indonesia yang layak untuk diterapkan pada industri pariwisata di Indonesia.

Penelitian ini mencoba memetakan indikator pelayanan makanan dan minuman pada pesta pernikahan adat masyarakat tradisional sebagai daya tarik wisata berbasis masyarakat dengan menggali potensi khasanah kekayaan budaya tradisional Indonesia untuk dikembangkan menjadi atraksi wisata budaya, di samping untuk melestarikan warisan budaya asli Nusantara.

Dengan semakin meluasnya penggunaan teknik pelayanan dari negaranegara barat seperti American Service ataupun Buffet Service (Prasmanan) di komunitas masyarakat adat. Padahal pada kenyataannya Indonesia memiliki sistem, nilai dan karakter budaya yang beragam yang berpotensi untuk diangkat dan dipopulerkan sebagai teknik pelayanan etnik Nusantara maka rumusan masalah dalam penelitian ini adalah sebagai berikut:

1). Bagaimana prosesi persiapan pelayanan makanan dan minuman pada pesta pernikahan pada masyarakat Batak Toba, Baduy Luar, dan Sasak Lombok?

2). Bagaimana filosofi yang terkandung dalam tata cara penyajian makanan dan minuman pada pesta adat tersebut?

3). Apa saja indikator dari pelayanan makanan dan minuman pada acara pernikahan di masyarakat adat tersebut yang berpotensi menjadi daya tarik sebagai pariwisata berbasis masyarakat?

Berdasarkan rumusan masalah tersebut, maka tujuan penelitian ini adalah sebagai berikut:

1) Untuk mengetahui prosesi persiapan pelayanan makanan dan minuman pada pesta pernikahan pada masyarakat Batak Toba, Baduy Luar, dan Sasak Lombok! 
2) Untuk memahami nilai-nilai filosofi yang terkandung dalam tata cara penyajian makanan dan minuman pada acara pernikahan adat tersebut!

3) Untuk memetakan indikator pelayanan makanan dan minuman pada acara pernikahan adat tersebut yang berpotensi menjadi daya tarik wisata berbasis masyarakat!

\section{METODOLOGI PENELITIAN}

Desain penelitian ini adalah penelitian deskriptif kualitatif, di mana metode pengumpulan data dilaksanakan melalui, observasi, wawancara, angket, dan studi literatur. Namun karena keterbatasan waktu dan ruang dengan kondisi pandemik saat ini, maka peneliti tidak bisa melakukan observasi langsung ke Pulau Samosir sehingga pengumpulan data dilakukan dengan mengirim daftar pertanyaan beserta instrument penelitian secara daring kepada informan di Pulau Samosir.

Data primer pada penelitian ini adalah seluruh data yang diambil pada saat persiapan, pelaksanaan, dan berakhirnya acara pelayanan makanan dan minuman pada upacara pernikahan di masyarakat adat sedangkan data sekunder bersumber dari penelitian terdahulu dan berbagai data yang diklasifikasikan sebagai data internal (berasal dari dalam desa itu sendiri) dan data eksternal (berasal dari luar desa atau masyarakat) seperti: publikasi pemerintah, jurnal, artikel, buletin, buku, surat kabar, atau data sindikat. Adapun sumber data dalam penelitian ini adalah Kepala Desa tokoh masyarakat dan penggiat wisata budaya Desa Rambitan, tokoh adat Desa Tomok Samosir, tokoh adat dan kelompok penggiat wisata budaya Desa kenekes, Baduy Luar, dan kelompok penggiat wisata budaya Desa Tomok Kabupaten Samosir.

Penelitian ini berlangsung selama kurang lebih 4 (empat) bulan dimulai pada bulan Juni 2020 dan selesai pada bulan November 2020. Teknik pengumpulan data dalam penilitian ini yaitu dengan cara observasi, melalui informan, studi literatur (dokumentasi). Subjek dari penelitian ini adalah masyarakat tradisional sedangkan objek dari penelitian ini adalah pelayanan makanan dan minuman pada pesta pernikahan di masyarakat adat tersebut.

\section{HASIL DAN PEMBAHASAN}

\subsection{Persiapan pelayanan makanan dan minuman pada pesta pernikahan pada Masyarakat Adat Desa Tomok, Simanindo, Samosir.}

Menurut Poniton Purba, tokoh pemuda Desa Tomok Simanindo, Samosir, bahwa dalam persiapan pelayanan makanan dan minuman pada pesta pernikahan dilakukan oleh: Parhobus : warga sekitar pihak laki-laki dan karyawan katering dan Parboru: para Ibu yang semarga dengan Bapak mempelai laki-laki.

Ada pun tata cara penyajian makanan adalah: makan siang pukul 13.00 biasanya dengan prasmanan atau makan bersama, dilanjutkan dengan pemberian kopi/teh dan Lapet/kacang pada pukul 15.30. Yang terlibat dalam pelayanan makanan dan minuman adalah "Parhobas" bisa dari masyarakat sekitar yang ditunjuk. Biasanya acara makan bersama. Para "Parhobas" melayani tamu-tamu dan keluarga kedua pengantin dibantu karyawan katering, karena zaman sekarang ini penyiapan makanan diserahkan sama pihak katering. Makanan yang disajikan biasanya makanan tradisonal antara lain: 
1) Saksang: daging babi yang dimasak dengan menggunakan darah.

2) Ikan mas Arsik: ikan bumbu kuning. Dimasak dengan menggunakan rempah asli dari Sumatera Utara, yaitu "Andaliman".

3) Ayam Qota: daging ayam yang dimasak dan dibumbui dengan darah ayam.

4) Sayur urap. daun ubi tumbuk., dan Lapet dan kacang.

\subsection{Persiapan pelayanan makanan dan minuman pada pesta pernikahan pada Masyarakat Adat Baduy Luar, Lebak, Banten}

Masyarakat Baduy Luar sangat sederhana dalam menjalani kehidupan dan sangat lekat dengan alam sehingga dalam acara acara adat pun mereka lebih mengutamakan kesederhananaa dan lebih banyak berinteraksi dengan alam sekitar. Mungkin ini sesuai dengan gaya hidup mereka yang sederhanya, dan tidak berbeda pada saat acara pesta pernikahan, menurut tokoh pemuda pada masyarakat suku Baduy Luar yaitu Kang Udil, bahwa mereka dalam melaksanakan pernikahan sangat sederhana, mereka tidak melaksanakan pesta seperti masyarakat di luaran (modern) tapi suku Baduy Luar hanya menjamu para tokoh masyarakat (Pu-un, Bapa Kolot, Kolot dan Jaro). Baduy Luar maupun Badui Dalam dan masyarakat lainnya biasanya hanya menikmati sajian seadanya dan secara sederhana.

Menurut Kang Udil dan Kang Yuli (tokoh pemuda Baduy Dalam) bahwa masyarakat Baduy Luar sudah harus dinikahkan pada usia kurang lebih 15 tahun bagi wanita dan telah mampu mengelola ladang bagi laki-laki (kurang lebih 16-17 tahun). Sementara masyarakat Baduy Dalam menikah setelah pemuda-pemudi mereka dijodohkan sejak masih balita. Bahkan pada saat ada bayi lahir maka akan dipertemukan dengan jodohnya oleh pemimpin adat yaitu para $\mathrm{Pu}$-un, sementara masyarakat Baduy Luar telah dibolehkan memilih jodoh di kalangan mereka.

Makanan dan minuman masyarakat Baduy Luar sangatlah sederhana (simple), mereka hanya mengandalkan hasil ladang mereka, termasuk pada saat acara pernikahan, sebagai contoh, peneliti mendapat informasi ketika pernikahan Marsha, anak wanita dari Kang Udil, pernikahan ini banyak diunggah oleh para Youtuber, karena pernikahan unik suku Baduy Luar yang mana Marsha berusia 15 tahun sementara suaminya berusia 16 tahun (kurang lebih). Dalam acara pernikahan tersebut, makanan yang disajikan oleh Lancuran (yang punya hajat adalah: Pisang, Dodol, Wajik, rengginang, untuk lauk ikan asin, ayam panggang, Rumbui (yaitu Pisang bakar, dicampur dengen nasi akeuh/dikipasin, kemudian dikepal-kepal), Gensot, yaitu Singkong dicacah lalu dicampur dengan kelapa dikeukur (sejenis parut khas masyarakat Baduy Luar) lalu dimakan bersama gula aren.

Pesta pernikahan masyarakat Baduy Luar, hanya melayani tokoh adat mereka yaitu para Pu-un, Bapa Kolot, Kolot, Jaro. Istilah istilah di atas adalah hirarki kepemimpinan suku Baduy Luar yaitu yang tertinggi adalah Pu-un, hanya dipegang oleh masyarakat Badui Dalam, sementara dibawahnya adalah Bapak Kolot dan Kolot, kemudian sebagai pemimpin pada masyarakat Baduy Luar adalah Jaro. Jaro inilah sekaligus sebagai penghubung anatar masyarakat Baduy Luar dan Badui Dalam secara spiritual.

Pesta pernikahan, para ibu mempersiapkan segala jenis masakan yang sederhana tersebut dan akan disajikan kepada para tokoh masyarakat dengan 
makan bersama, yaitu makanan diletakkan di satu tempat Tadah Adat, yaitu piring panjang dan setiap orang tokoh disajikan satu ekor ayam kampung, ditemani oleh sajian lainnya, sementara yang melayani adalah masyarakat setempat yang disebut Pala wali.

Sehubungan sifat yang tertutup pada masyarakat Baduy Dalam, dan bahkan Baduy luar sekalipun mereka sangat terbatas dalam memberikan informasi, maka penelitian ini mengalami keterbatasan untuk memperoleh data yang lengkap pada masyarakat Baduy Luar.

\subsection{Persiapan pelayanan makanan dan minuman pada pesta pernikahan pada Masyarakat Adat Desa Rembitan, Lombok}

Hasil wawancara peneliti dengan informan yang ada di desa Rembitan, bahwa menurut H. Edan yang bertugas sebagai Agan, yaitu kepala tukang masak dan Bapak Lalu Minaksa (Kepala Desa Rembitan) bahwa dalam persiapan pesta pernikahan, selain menyiapkan Agan, Ran, Belian/Pemangku yang tidak kalah pentingnya harus dikoordinasikan adalah Banjar (pelayan makanan dan minuman) biasanya menunjuk pemuda desa, yang biasanya mereka juga disebut Ancangan. Suguhan yang disajikan dalam pesta pernikahan di Desa Rembitan berupa Belanggi, yaitu jajanan yang disajikan sebelum makanan utama.

Menurut Lalu Limar (Ran) yang bertugas saat itu bahwa, masakan yang disiapkan adalah sayur ares (debong/batang pohon pisang) dan masakan daging sapi. Uniknya di desa ini, masakan hanya disebut sesuai dengan jenis atau bahan yang digunakan, misalnya Jangan Sampi yang berarti makanan tersbuat terbuat dari daging sapi, Jangan Kao yaitu berbahan dasar kerbau, ada juga Jangan Bembek dengan bahan dasar kambing, atau Manuk dengan bahan ayam dan lain sebagainya, ini berbeda dengan di daerah lain, masakan memiliki nama berbeda walau bahan dasarnya sama. Adapun bumbu yang digunakan hanya menggunakan bumbu dasar (bumbu jangan) yaitu bumbu dasar yang terbuat dari rempahrempah seperti bawang putih, bawang merah, jahe, laos dan kunyit, ditambah cabe, terasi, dan daun salam, yang menjadi ciri dari penyajianya adalah jumlah kuah yang ada disekitar jangan tersebut.

H. Edan menyebutkan bahwa kuah yang disajikan bersamaan dengan jangan dalam rangkaian penataan makanan adalah berjumlah 9 (sembilan) jenis kuah, yang diwadahi daun berbentuk pincuk, kemudian disajikan di atas nampan besi/tray dengan nasi di piring sejumlah yang akan makan bersama/Begibung. Proses penyajian makanan tersebut dilakukan oleh Ancangan.

Di Desa Rembitan, pesta pernikahan menggunakan sistem "Begibung" seperti halnya dengan sebagian besar tradisi masyarakat Sasak tradisional lainnya. Tahapan pelayanan "Begibung" pada masyarakat Rembitan dilakukan sebagai berikut:

1) Pelayanan makanan menggunakan nare/nampan terbuat dari besi yang berisi 2 (dua) piring nasi dan 2 (dua) piring lauk.

2) Tamu datang dipersilahkan duduk oleh Ancangan, kemudian disuguhi kopi (terutama tamu pria) dan sirih bagi yang wanita.

3) Kemudian disuguhi Belanggi, yaitu berbagai jenis kue tradisional (jajan) juga menggunakan Nare dan setiap kue ditata di atas piring saji. 
4) Setelah selesai Belanggi, lalu disuguhkan makanan yang isinya nasi dan jangan/lauk dan sayur.

5) Khusus tamu-tamu penting (VIP) disuguhkan menggunakan Pesajik, yaitu makanan di atas dulang nampan berkaki, dengan 2 piring nasi, jangan sampi, jangan bembeq, jangan manuk dan ares, disertai kuah yang berjumlah 9 pincuk.

6) Makanan dan minuman untuk tamu penting (VIP) berbeda dengan undangan dari masyarakat biasa..

\subsection{Filosofi dan makna tata cara penyajian makanan dan minuman pada acara pernikahan masyarakat adat.}

Pada Masyarakat Adat Desa Tomok, Simanindo, Samosir, makanan untuk pengantin, dalam pemberian makanan disertai dengan kalimat nasehat dan doa semoga kedua pengantin hidup bahagia, menjadi pasangan seumur hidup (saur matua), sedangkan makanan untuk tamu undangan dihidangkan dengan menu catering oleh karyawan perusahaan catering yang terdiri atas daging saksang, nasi beserta sayur. Adapun filosofi untuk berbagai hidangannya adalah sebagai berikut: Tudu-tudu Sipanganon, terdiri atas: kepala utuh, leher (tanggalan), rusuk melingkar (somba-somba), pangkal paha (soit), punggung dengan ekor (upasira), dan hati serta jantung. Hidangan ini dipersiapkan pihak keluarga laki-laki untuk diserahkan kepada pihak keluarga perempuan. Tudu-tudu Sipanganon ini merupakan simbol penghormatan kepada pihak perempuan dan ini juga merupakan tanda bahwa upacara adat dimulai. Hidangan ini dibuat di dalam baskom besar atau piring besar dan posisi babi dibuat layaknya babi hidup, yaitu kepala di depan dan ekor di belakang. Selanjutnya ada menu Ikan Mas Arsik, karena ikan hidup di air bersih/jernih dan kalau berjalan/berenang selalu beriringan (mundur-mundur) dengan alasan inilah disebut "dekke sitio-tio/dekke si mundur-mundur". Keunikan (uniqeness) simbol inilah yang menjadi harapan kepada pengantin dan keluarga supaya murah rezeki atau rezeki lancar seperti air dan kedua pengantin bisa hidup beriringan/berdampingan seperti ikan yang dimaksud. Ikan mas Arsik ini disediakan pihak perempuan untuk diberikan kepada pihak laki-laki sebagai balasan atas pemberian "Tudu-tudu Sipanganon". Prosesi acara "Adat Na Qok" atau "Adat Penuh". Terdapat semboyan adat Batak pada acara ini, yaitu prinsip Dalihan Na Tolu, yaitu "Somba Marhula-hula, Elek Marboru, dan Manat Mardongan Tubu". Yang artinya dalam bahasa Indonesia: Somba Marhulahula: hormat kepada hula-hula (keluarga dari pihak perempuan), Elek Marboru: Sayang kepada boru. Boru adalah anak perempuan. Manat Mardongan Tubu: sopan dengan tubu (dongan tubu adalah semarga atau seketurunan). Filisofi yang terkandung di sini adalah filosofi kesetaraan gender dan filosofi semangat persatuan bagi masyarakat yang satu keturunan.

Pada masyarakat Baduy Luar, filosofi kesederhanaan sangat terlihat pada tampilan aneka makanan yang disajikan, baik proses pembuatan makanan maupun bahan makanan yang hanya mengandalkan hasil ladang/alam yang ada di tengah hutan milik mereka. Makanan yang paling mewah (worthy) di kalangan suku Baduy Luar, juga Baduy Dalam, adalah ikan asin dan garam, maka mereka sangat senang bila ada yang memberi mereka oleh-oleh ikan asin dan garam. Makanan yang disajikan mulai dari Rumbui, Gengsot, ikan asin, dodol, wajik, rengginang, 
semuanya melambangkan kesederhanann dan menyatunya masyarakat Baduy Luar dengan alam.

Pada masyarakat Desa Rembitan, Lombok Tengah, sebagaimana dijelaskan oleh Tuan Guru Haji Lalu Mohammad Abdul Gani seorang tokoh agama di Desa Rembitan sebagai berikut: sebelum masuknya Islam waktu lima, masyarakat Rembitan menganut Islam wetu telu, dan pada zaman itu pernikahan diawali dengan Tobat Bareng, yaitu kedua mempelai dihadapan pemuka agama mengangkat sumpah dengan kalimat syahadat, sebelum mereka dinikahkan, pada saat tobat bersama tersebut, masyarakat berpesta dengan menyuguhkan Ayam Merangkat, yaitu daging ayam yang dilumuri bumbu sambal yang sangat pedas. Kemudian sesuai perkembangan zaman, tobat bersama itu hilang setelah seluruh masyarakat Rembitan menjalankan/berislam sesuai dengan Islam yang sebenarnya atau adanya perspektif halal. Penyajian makanan Begibung disuguhkan jangan, dengan sajian kuah yang menggunakan wadah 9 pincuk, itu melambangkan Wali Songo, yang mana mungkin pada zaman dahulu penyebaran Islam ke tanah Lombok ini dilakukan oleh Wali Songo, sehingga diabadikan dalam perayaan pesta pernikahan. Menurut Tuan Guru Abdul Gani, angka Sembilan adalah angka sempurna sehingga pernikahan merupakan perjalanan manusia menuju kesempurnaan, sebab sebelum manusia menikah, belum dapat disebut sebagai manusia sempurna.

\subsection{Potensi Pelayanan Makanan dan Minuman Pada Acara Pernikahan Masyarakat Sasak, Batak Toba, dan Baduy Luar Sebagai Daya Tarik Pariwisata Berbasis Masyarakat.}

Yang menjadi indikator daya tarik wisata pada pesta pernikahan masyarakat Tomok adalah: Prosesi acara "Adat Na Qok" atau "Adat Penuh" dan acara pesta perjamuan adat. Jenis makanan yang disajikan beupa makanan khas masyarakat Batak Toba, yaitu: Saksang: daging babi yang dimasak dengan menggunakan darah dan Ikan mas Arsik: ikan bumbu kuning. Dimasak dengan menggunakan rempah asli dari Sumatera Utara, yaitu "Andaliman", Ayam Qota: daging ayam yang dimasak dan dibumbui dengan darah ayam, sayur urap, daun ubi tumbuk, Lapet dan kacang.

Pada masyarakat Baduy Luar, indikator yang paling menarik adalah kesederhanaan masyarakatnya, bahkan dalam pesta pernikahan mereka tidak menggunakan berbagai peralatan teknologi moderen, hanya saja masyarakat Baduy Luar sudah sedikit tersentuh oleh teknologi, maka pesta pernikahan Marsha dapat terabadikan dalam photo dan video yang banyak diunggah oleh Youtuber di jagat maya, namun pesta pesta yang terdahulu, hampir tidak terdokumentasi, termasuk makanan dan sajian serta cara menyajikan makanan, justru menurut pendapat peneliti, inilah bagian yang paling menarik dari prosesi pesta pernikahan masyarakat Baduy Luar.

Pada pesta pernikahan di desa Rembitan, indikator yang dapat peneliti temui adalah sebagai: 1) Masakan yang disajikan, mulai dari Belanggik, yaitu kue-kue tradisional yang sangat eksotis dan khas, selanjutnya lauk yang tanpa nama, atau lebih tepatnya hanya menggunakan nama sesuai bahan dasar dari lauk tersebut, kemudian untuk tamu penting ditambah 9 kuah yang bumbunya relatif sama; 2) Pelayanan Begibung yang khas desa ini, yaitu makanan untuk masyarakat 
kebanyakan berupa dua piring lauk dan nasi dihidangkan sesuai jumlah tamu yang akan menikmati, yaitu dua sampai tiga orang; 3) Peralatan yang digunakan, adapun peralatan yang digunakan pada pesta pernikahan di sini, mengalami perubahan dari masa ke masa, sebelum dikenal berbagai peralatan besi seperti saat ini, penyajian makanan menggunakan Ancak, yaitu berupa anyaman bambu yang dialasi daun pisang, perkembangan selanjutnya masyarakat menggunakan Dulang, yaitu nampan kayu berkaki, dengan alas daun, dan pada saat ini menggunakan nampan, dengan alas piring sesuai jumlah nasi dan lauk, hanya VIP masih menggunakan nampan berkaki dan alas daun.

Sehubungan dengan keterbatasan waktu, pembatasan sosial di masa pandemi ovid-19 dan pelaksanaan protokol kesehatan, maka kelengkapan data pada penelitian ini masih terbatas. Pada masyarakat Desa Tomok, pernikahan yang mereka anut adalah merupakan pernikahan tradisional masyarakat Batak Toba yang telah dijiwai oleh agama Kristiani, yang mana prosesi di gereja merupakan prosesi utama, di samping pesta adat pernikahan yang menyajikan berbagai makanan tradisional bernuansa Batak Toba. Berbeda dengan masyarakat Baduy Luar dengan ciri khas kesederhanaan mereka dan menyatunya kehidupan mereka dengan alam, yang membuat pesta pernikahan mereka sangat sederhana, tidak ada upacara keagamaan layaknya agama yang dianut sebagian besar masyarakat Indonesia, hanya diiringi ritual adat dan doa-doa kepada Tuhan Yang Maha Esa, dan tanpa pesta mewah. Para pelayan (Palawali) yang melayani pesta juga berpakaian sederhana, cukup menggunakan pakaian sederhana, sarung khas Baduy dan ikat kepala (telekung) putih/hitam bagi Baduy Dalam dan ikat kepala (Long Mar) berupa batik berwarna biru bagi Baduy Luar.

Sementara masyarakat Rembitan di Pulau Lombok, sangat kental dengan nuansa Islami, walaupun adat istiadat masyarakat Sasak bahkan keyakinan lama masayarak Sasak (Wetu Telu) masih mewarnai dari pesta pernikahan masyarakat Rembitan,. Adapan sajian yang disajikan sangat kental masakan khas Lombok, namun mengandung filosofi Islami yaitu daging dan sayur disajikan dengan 9 (sembilan) kuah yang melambangkan 9 Wali (Wali Songo) yang menyebarkan agama Islam di Lombok.

Berdasarkan pembahasan tersebut, pesta pernikahan terutama pelayanan makanan dan minuman pada masyarakat tradisional Indonesia, data dikolaborasikan, dan dikembangkan menjadi satu daya tarik pada pelayanan makanan dan minuman untuk berbagai pesta pernikahan dari berbagai kalangan, misalnya kesederhanaan makanan masyarakat Baduy Luar, dapat dijadikan bagian dari camilan (snack corner) pada buffet dan kemewahan makanan masyarakat Samosir yang dipadukan dengan rempah-rempah masakan Rembitan sebagai makanan utamanya (main course). Indikator yang menarik adalah tata cara pelayanan Begibung pada masyarakat Sasak di Lombok, dipadukan dengan pelayanan khusus untuk para $\mathrm{Pu}$ un di tengah masyarakat Baduy Luar akan menjadi sebuah suasana pesta yang bernuansa berbeda dari pesta-pesta yang pernah ada, termasuk pesta yang ada di Batak-Samosir. 


\section{KESIMPULAN}

Prosesi persiapan pelayanan makanan dan minuman pada pesta pernikahan masyarakat tradisional Batak Toba, Baduy Luar, dan Sasak_Lombok memilki keunikan masing masing, dengan benang merah yang terlihat pada proses penyiapan masakan, pemilihan menu, penentuan tukang masak, sampai dengan tamu yang akan diundang. Masing masing daerah sangat unik, namun dalam proses penyiapan makanan peneliti belum temukan penerapan standard CHSE (Cleaning, Hygiene, Safety and Environment).

Filosofi dan makna yang terkandung dalam tahapan pesta pernikahan ke tiga masyarakat tersebut menunjukkan bahwa masyarakat Batak Toba dipengaruhi oleh budaya Belanda (Eropa), sementara masyarakat Baduy Luar menjadikan alam sebagai pelindungnya, dan masyarakat Sasak memadukan dengan apik hubungan adat istiadat dengan budaya Islami.

Adapun indikator dari pelayanan makanan dan minuman pada acara pernikahan masyarakat Batak Toba, Baduy Luar, dan Sasak Lombok yang berpotensi menjadi daya tari pariwisata berbasis masyarakat adalah sebagai berikut: penyajian makanan yang unik, aneka jenis makanan yang berbeda dari satu tempat ke tempat yang lain, serta penyajian dan keunikan pesta adat mereka, ini sebagai daya tarik pariwisata berbasis masyarakat.

Persiapan pelayanan makanan dan minuman pesta pernikahan pada masyarakat tradisional harus mulai menerapkan standar CHSE untuk kesehatan para tamu dan keluarga pengantin, serta agar memenuhi syarat untuk menjadi daya tarik pariwisata berbasis masyarakat.

Filosofi makanan berbagai daerah diharapkan makin banyak peneliti atau akademisi yang mengangkat sebagai tulisan karya ilmiah sehingga di masa yang akan datang, masyarakat tradisional melestarikannya dan para peneliti mempopulerkan sebagai kajian Gastronomi global.

Untuk dapat menjadi lebih menarik sangat dibutuhkan campur tangan (political will) dari pemerintah, pihak swasta, pihak media maupun kalangan akademisi untuk terus mengangkat daya tarik wisata berbasis masyarakat terutama pada pesta pesta tradisional.

\section{DAFTAR PUSTAKA}

Andi, P. (2014). Metode Penelitian Kualitatif. Ruzz Media. Yogyakarta.

Davis, B., Lockwood, A., Alcott, P., Pantelidis, L. (2012). Food and Beverage Management. Fifth Edition. Routledge. London.

Hamzah, A. (2019). Penelitian berbasis proyek, Metode kuantitatif, kualitatif dan $R \& D$. Cv.Literasi Nusantara Abadi, Malang

Kartini, Kartono. (1990). Pengantar Metodologi Riset Sosial. Mandar Maju Bandung.

KBBI Daring. (2016). Kamus Besar Bahasa Indonesia. Badan Pengembangan dan Pembinaan Bahasa, Kementerian Pendidikan dan Kebudayaan Republik Indonesia. https://kbbi.kemdikbud.go.id/. Diunduh tgl 25 April 2020 pukul 09.15 Wita.

Kotschevar, L. H. dan Luciani, V. (2007). Presenting Service, The Ultimate Guide for The Foodservice Profesional. Second Edition. Wiley \& Son, Canada.

Lillicrap, D. \& Cousinss, J. (2014). Food \& Beverage Service, 9th Edition. Dynamic Learning. Hodder Education. The Food and Beverage Training Company, 
London. $\quad$ ISBN: $\quad 978 \quad 1444 \quad 11250 \quad 4$. https://www.google.com/url?sa=t\&rct=j\&q=\&esrc=s\&source=web\&cd=\&c ad=rja\&uact=8\&ved=2ahUKEwiigq3SuaLwAhWGSH0KHYJVAvkQFjAAegQI BhAD\&url=http\%3A\%2F\%2Fdocshare04.docshare.tips\%2Ffiles\%2F28421 \%2F284210720.pdf\&usg=AOvVaw0-OInV7xKLXjp9Cpq_7qS3. Diunduh tanggal 29 April 2021 pukul 11.5 Wita/

Masyhuri dan Zainuddin, M., (2011), Metodologi Penelitian. Pendekatan Praktis dan Aplikatif. Edisi Revisi. Refika Aditama. Malang

Moleong, J. Lexy. (2019). Metodologi Penelitian Kualitatif PT.Remaja Rosdakarya Bandung

Nasir, M. (2011). Methodology Penelitian, Ghalia Indonesia, Jakarta

Ninemeier, J.D., Hayes, D.K. (2010). Restaurant Operations Management, Principal and Practices. Pearson, Prentice Hall. New Jersey, USA. ISBN-10: 086612344X, ISBN-13: 97808661-23440

Ninemeier, J.D. (2015). Management of Food and Beverage Operations, Sixth Edition eBook. AHLEI. USA. ISBN 978-1-949324-37-2

Prasiasa, O.P.D, (2012) Pariwista Berbasis Masyarakat, Bali; Humanika Salemba. Jakarta

Radjab, R. (2019), Halal Tourism: Unique, Simple and Worth It, The Atlantis Press, Paris ISBN: 978-94-6252-879-6 https://doi.org/10.2991/icoborot18.2019.11

Ramdah, Dirga, dkk. (2019). Begibung sebagai Atraksi Wisata pada Upacara Adat Masyarakat Desa Bayan Kabupaten Lombok Utara dan Pagringsingan Tenganan Candidasa Kabupaten Karangasem Bali. Prodi Tata Hidang Politeknik Pariwisata Lombok. Praya.

Strianese, A., J. (2007). Dining Room and Banquet Management, fourth edition. Delmar Publisher. London.ISBN: 0-8273-7566-2

Sugiono. (2015). Memahami Penelitian Kulaitatif. CV Alfabeta Bandung.

Vargouwen. J, C (2019). Masyarakat adat dan Hukum adat Batak Toba, Pustaka Azet, Jakarta.

Walker, J. R. (2013). The Restaurant: From Concept to Operation, 7th Edition. John Wiley \& Sons, Incorporated. ISBN1118802985, 9781118802984. London

Yusuf. (2014). Metode Penelitian Kuantitatif, kualitatif dan Penelitian Gabungan. Prena Media Group. Jakarta.

Yaniningsih, S. (1986) Arti Lambang dan Fungsi Tata Rias Pengantin Dalam Menanamkan Nilai Nilai Budaya daerah Nusa Tenggara Barat. Dept. Pendidikan dan Kebudayaan. NTB.

Goodman Jr. Raymond J. (2002). F\&B Service management. Penerbit Erlangga Jakarta (edisi ke 2)

https://ejournal.undiksha.ac.id/index.php/JJPKK/article/view/9911

https://en.wikipedia.org/wiki/Badui Luar_people

https://kumparan.com/kumparantravel/7-fakta-unik-tradisi-seba-Badui Luaryang-perlu-kamu-tahu-1t135Jf0bwu

https://travel.kompas.com/read/2020/02/12/111250727/seba-Badui Luartradisi-ratusan-tahun-masyarakat-Badui Luar-syukuri-hasil-bumi?page=all https://travel.kompas.com/read/2020/05/31/131124727/lebak-batallaksanakan-tradisi-seba-Badui Luar?page=all 
https://bobo.grid.id/read/08673659/tuk-tuk-samosir-kampung-turis-di-danautoba

https://phinemo.com/14-aktivitas-yang-membuat-liburanmu-di-tuk-tuk-samosirjadi-lebih-berkesan/ 